Bull. Mater. Sci., Vol. 5, No. 5, December 1983, pp. 381-387. (C Printed in India.

\title{
Crystal growth of barium molybdate by flux evaporation
}

\author{
S K ARORA and G S TRIVIKRAMA RAO \\ Department of Physics, Sardar Patel University, Vallabh Vidyanagar 388 120, India \\ MS received 27 September 1982.
}

\begin{abstract}
Single crystals of $\mathrm{BaMoO}_{4}$ have been grown by isothermal evaporation of lithium chloride at $700^{\circ} \mathrm{C}$. The morphology and mechanism of growth of the crystals have been discussed. The quality of the crystal has been assessed by selective etching.
\end{abstract}

Keywords. Barium molybdate; flux evaporation; morphology; growth mechanism; etching.

\section{Introduction}

Barium molybdate belongs to an interesting (morphotropic and isostructural) series of Scheelite-type crystals of space group $C^{6} 4 h$ or $I 4_{1 / a}$ (Wycoff 1951) and finds wide applications in optics, acoustics and electronics. Crystals of $\mathrm{BaMoO}_{4}$. have been grown by hydrothermal (Litvin et al 1966), pulling ( $T u$ chen 1973) and gel (Cho et al 1977) methods, but with limited success. Packter and Roy $(1971,1975)$ reported crystallization studies of $\mathrm{BaMoO}_{4}$ precipitates from lithium chloride melts but were not concerned with the size and purity of their products. This paper reports attempts to grow larger and better single crystals of $\mathrm{BaMoO}_{4}$ by flux evaporation method and investigate their growth characteristics.

\section{Experimental and observations}

\subsection{Equipment and materials}

A vertical-tube muffle furnace was constructed with cylindrical alumina muffle wound by super kanthal heating element and covered by insulating bricks and lining. A stabilized power of $1.5 \mathrm{~kW}$ was used. A $25 \mathrm{ml}$ platinum crucible of $0.5 \mathrm{~mm}$ wall thickness was employed to contain the growth charge. The temperatures were monitored by $\mathrm{Pt}-\mathrm{Pt} / 10 \% \mathrm{Rh}$ thermocouple placed just below the crucible.

The chemicals used in the present study were : Sendez $\mathrm{Swijur}_{\mathrm{BaMoO}}$ powder of $99.6 \%$ purity and SD's reagent grade hydrated LiCl.

\subsection{Flux growth}

To induce supersaturation in the high temperature solution to onset free crystallization, (Roy 1966; Wood and White 1968; Webster and White 1969), 
isothermal solvent evaporation was preferred to slow cooling procedure. The results of different growth experiments (keeping the soak temperature of $700^{\circ} \mathrm{C}$ ) carried out using different cempositions and soak periods are shown in table 1 . The quantities of initial materials were properly weighed, mixed thoroughly using a pestle and morter and then packed into the crucible provided with a loosely fitting platinum lid. The charged crucible was placed in the furnace and the power turned on to bring a temperature of $750^{\circ} \mathrm{C}$. The mixture was heated at this temperature, which was $50^{\circ} \mathrm{C}$ higher than the soak temperature, for about $30 \mathrm{~min}$ to ensure complete
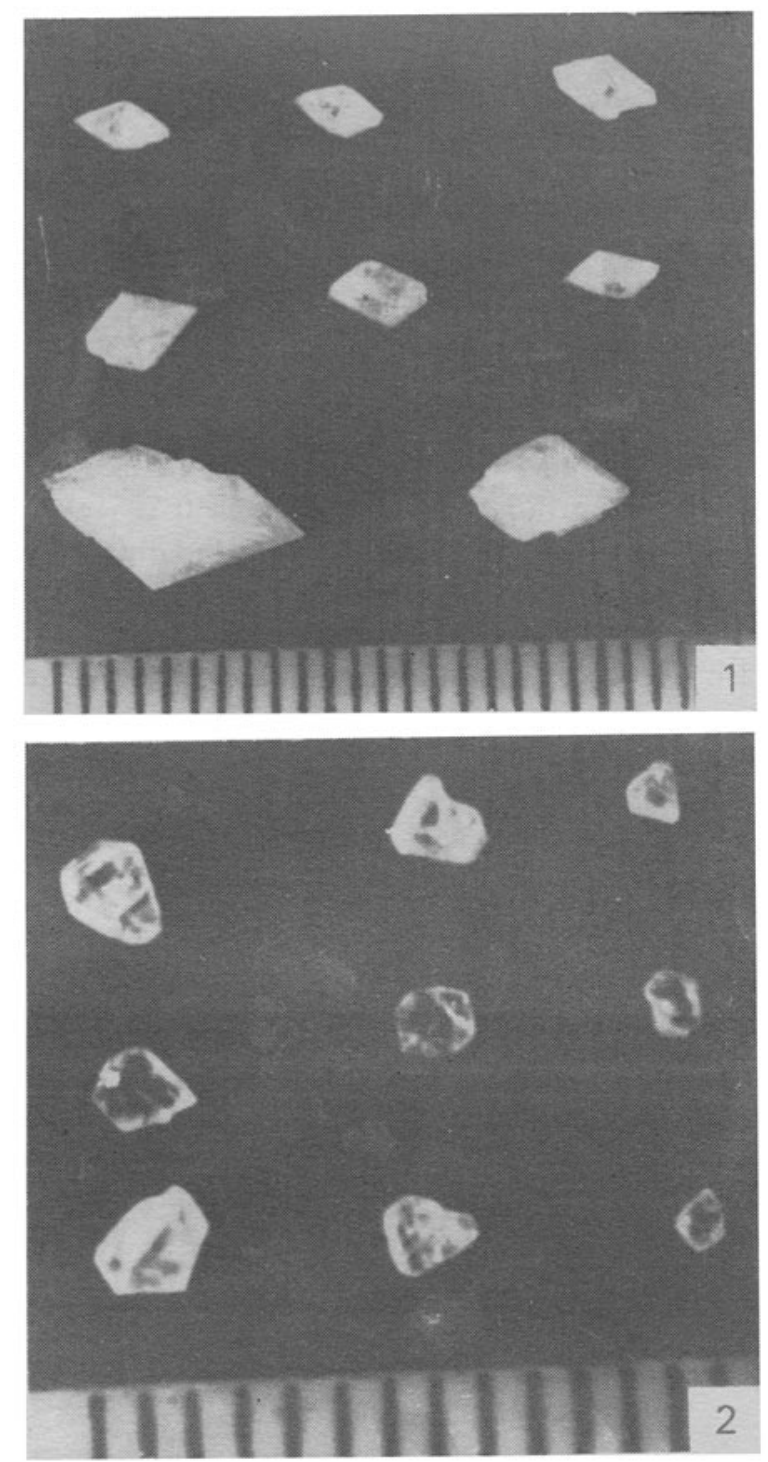

Figures 1-2. (scale: 1 div $=1 \mathrm{~mm}$ ) 1. A few bipyramidal crystals of $\mathrm{BaMoO}_{4}$. 2. Thin, platy crystals of $\mathrm{BaMOO}_{4}$. 
solution in the crucible. The temperature was then rapidly lowered to the soak temperature of $700^{\circ} \mathrm{C}$ and maintained for prolonged periods as specified in table 1 , thus allowing solvent evaporation to take place. Consequently, the crystal growth occurred at $700^{\circ} \mathrm{C}$. At the end of the soak periods, uniform cooling at the rate of $10^{\circ} \mathrm{C} \mathrm{hr}-1$ was carried out down to $500^{\circ} \mathrm{C}$ with a view to avoiding charge eruptions in the crucible. The furnace power was then put off and the crucible allowed to cool down to room temperature overnight. The contents of the crucible were then leached with hot distilled water which easily separated the insoluble crystals from the matrix of the solidified charge.

\section{Characterization}

\subsection{Crystal habits and properties}

Many good crystals of $\mathrm{BaMoO}_{4}$ of about $11 \mathrm{~mm}$ size, together with a number of smaller ones, were obtained. This size is, as usually expected, less than that of pulled crystals (TuChen 1973) but is indeed greater than others reported in literature (Litvin et al 1966; Cho et al 1977; Packter and Roy 1971, 1975). Figure 1 shows some typical well-developed bipyramidal $\mathrm{BaMoO}_{4}$ crystals, while figure 2 shows thin, transparent plates.

The crystal perfection was found to be dependent on soak period, while the crystal morphology was sensitive to the flux-to-solute ratio, as revealed by table 1 . Using the charge composition, as in the experiment $1(\mathrm{a}, \mathrm{b})$ in table 1 , bipyramidal crystals bounded by (011) faces were obtained, and a variation, particularly in respect of size and degree of transparency, with soaking time was observed. Another composition, in the experiment 2(a, b) in table 1, yielded thin, transparent platy crystals by $12 \mathrm{hr}$ of evaporation. And, the same charge resulted hopper crystals with spiral-like terraced depressions by $22 \mathrm{hr}$ of isothermal soaking.

The lattice parameters of the grown crystals were determined by $x$-ray diffraction techniques, which matched well with the literature values (Powder data file 1967). Some of the characteristics examined have been listed in table 2 .

Table 1. Correlation of crystal morphology, size and quality with growth parameters (Soak temperature : $700^{\circ} \mathrm{C}$ )

\begin{tabular}{|c|c|c|c|}
\hline $\begin{array}{r}\text { Sl. } \\
\text { No. }\end{array}$ & $\begin{array}{c}\text { Composition of starting } \\
\text { materials }\end{array}$ & $\begin{array}{l}\text { Soak } \\
\text { time } \\
\text { (hrs) }\end{array}$ & Results \\
\hline 1(a) & $\begin{array}{l}10 \mathrm{~g} \mathrm{BaMoO}+7.1 \mathrm{~g} \\
\mathrm{LiCl}, \mathrm{H}_{2} \mathrm{O}\end{array}$ & 12 & $\begin{array}{l}\text { Transparent, bipyramidal } \\
\text { crystals, up to } 1 \mathrm{~mm} \text { across }\end{array}$ \\
\hline (b) & Same as (a) & 50 & $\begin{array}{l}\text { Smoky and distorted } \\
\text { bipyramidal crystals } \\
\text { up to } 11 \mathrm{~mm} \text { across }\end{array}$ \\
\hline 2(a) & $\begin{array}{l}10 \mathrm{~g} \mathrm{BaMoO}_{4}+ \\
5.0 \mathrm{~g} \mathrm{LiCl} \mathrm{H}_{2} \mathrm{O}\end{array}$ & 12 & $\begin{array}{l}\text { Thin, transparent platy } \\
\text { crystals }\end{array}$ \\
\hline (b) & Same as (a) & 22 & Milky, hopper crystals. \\
\hline
\end{tabular}


Table 2. Some characteristic properties of $\mathrm{BaMoO}_{4}$ crystals.

\begin{tabular}{ll}
\hline Properties studied & $\mathrm{BaMoO}_{4}$ \\
\hline Maximum size obtained & $11 \mathrm{~mm}$ \\
Colour & Transparent to opaque \\
Habit & Tetragonal bipyramidal \\
$a=b=5.58 \AA$ \\
Unit cell dimensions & $c=12.79 \AA$ \\
& $3.55 \mathrm{mohs}$ \\
Average microhardness on $(011)$ plane & $4.9 \mathrm{~g} \mathrm{ml}^{-1}$ \\
Pycnometer density & $(001)$ \\
Cleavage & $2 \times 10^{3} \mathrm{~cm}^{-2}$ \\
Estimated dislocation density & 62.55 \\
Dielectric constant parallel to c-axis at & \\
room temperature $\left(35^{\circ} \mathrm{C}\right)$ and at $10^{2} \mathrm{~Hz}$ & $1.95 \times 10^{-10} \mathrm{ohm}-1 \mathrm{~cm}-1$ \\
DC conductivity at room temperature $\left(35^{\circ} \mathrm{C}\right)$ & \\
\hline
\end{tabular}

\subsection{Microtopographical characteristics}

The mechanism of crystal growth may, in general, be understood by either $x$-ray topography of sections through crystals (Authier 1972), measurement of growth rate as a function of supersaturation (Elwell and Dawson 1972) or observing the surface features. The as-grown (011) faces of the smaller (up to $1 \mathrm{~mm}$ size) crystals examined in the 'Epignost' optical microscope were found smooth and flat (figure 3 ) indicating that the mechanism of two-dimensional spreading and piling of growth layers across the crystal face is responsible for the growth of these crystals. This mechanism is supported by the complete absence of growth spirals on habit faces and by the movement of growth layers (figure 4) originated from the edges and corners. In fact, the sites of initiation of growth layers exist due to transport of solute by diffusion onto a growing crystal, thus creating a relatively higher supersaturation near the edges and corners of the crystals than in the middle (Chase 1968). The stability of the plane interface is to be interrupted by edge nucleation only, and the subsequent increase in supersaturation gradient leads to characteristic terraced depressions, as shown in figure 5, which probably arise as a result of propagation of densely packed lamellar sheets across the growing face. In the final stage of growth, due to the prevalent high degree of supersaturation and instability of the last layer of free surface, dendritic precipitation occurs on the faces. Most of the larger crystals ( $\geqslant 1 \mathrm{~mm}$ size) obtained exhibit typical dendritic patterns such as those shown in figure 6 .

\subsection{Etching}

The dislocation density in the grown crystals was determined by selective etch pits count on the only (001) cleavage face, employing $10 \%$ nitric acid solution as an etchant. The average dislocation density of $2 \times 10^{3}$ pits $\mathrm{cm}^{-2}$ reveals reasonable 

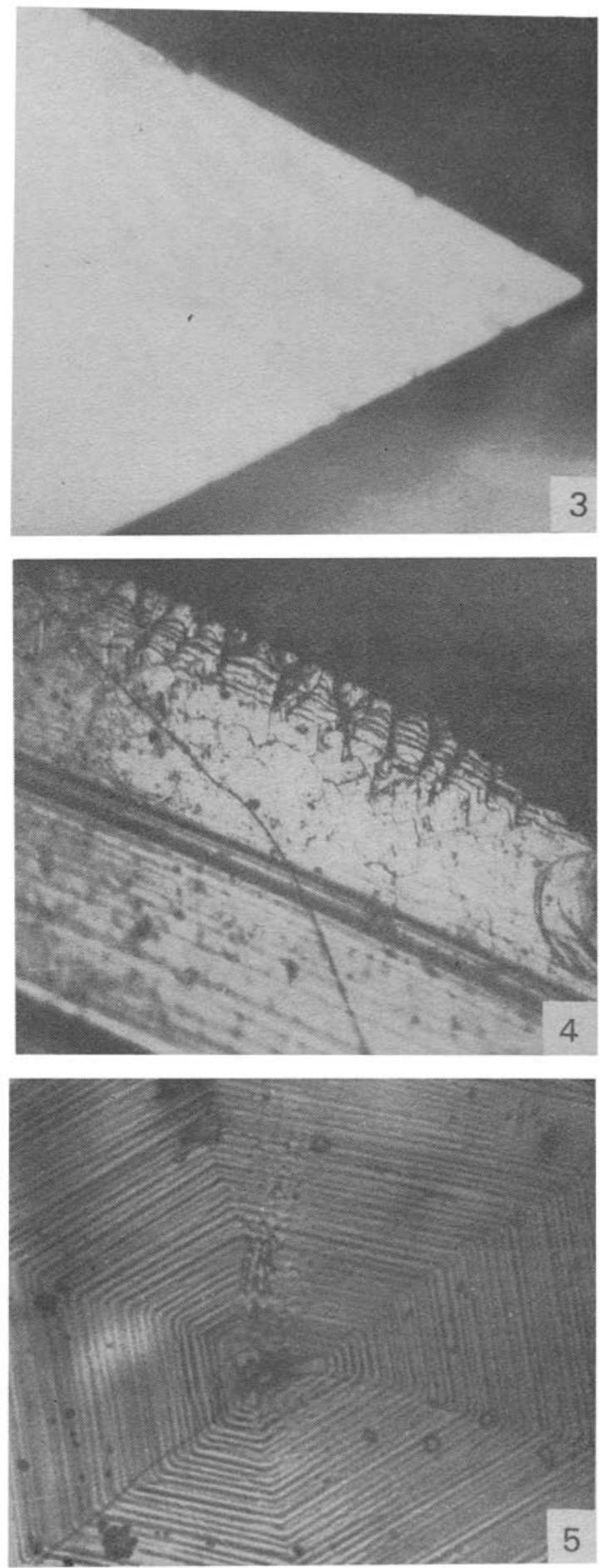

Figures 3-5. 3. A typical smooth and flat habit face of $\mathrm{BaMoO}_{4}$ crystal. 4. Layers originating from edges and corners of the grown faces. 5. Spiral-like terraced depression on the grown face. $(3,4 . \times 180,5 . \times 225)$. 

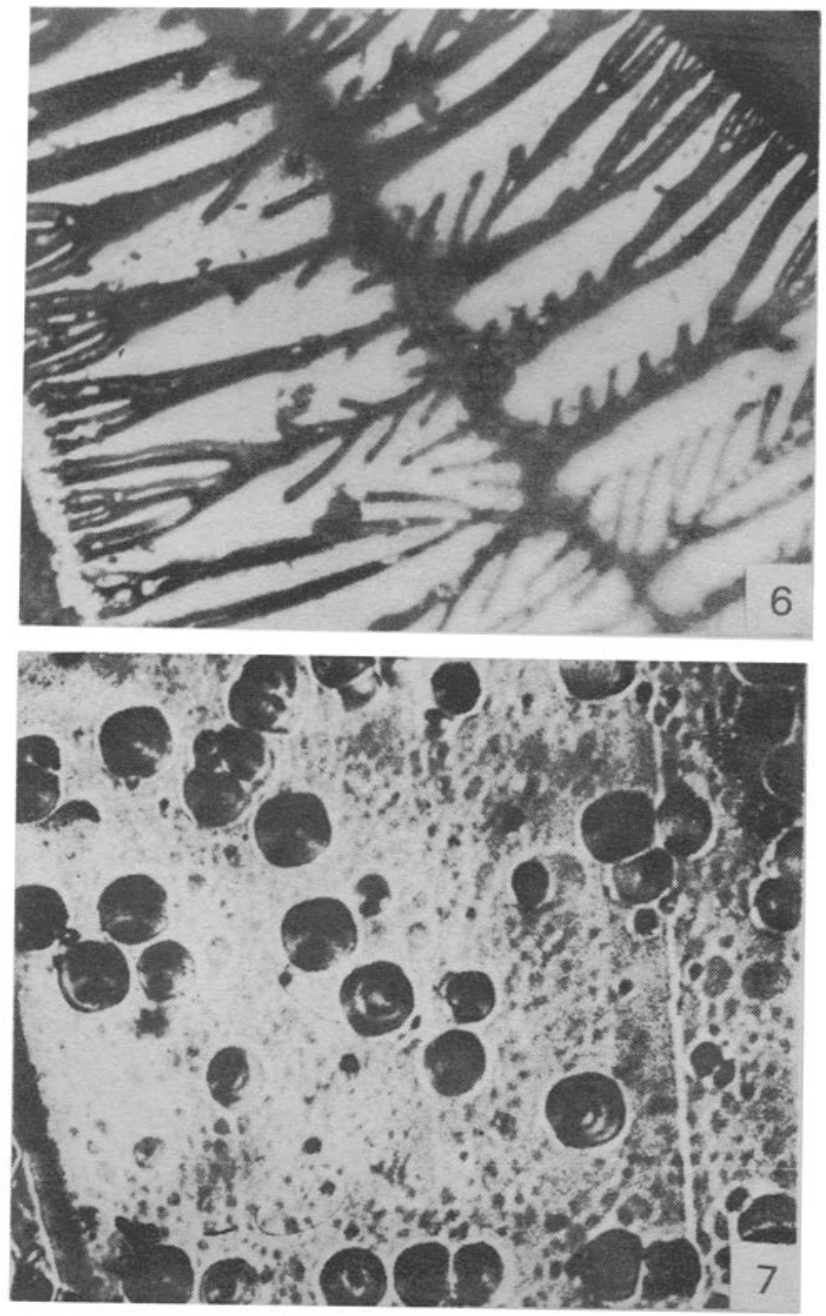

Figures 6-7. 6. Typical growth dendrites on the as-grown (011) face. 7. An etch pit pattern on $(001)$ cleavage plane. $(6 . \times 180,7 . \times 450)$.

perfection of the crystals and absence of low angle tilt-twist boundaries. A typical etch pattern on a cleavage face is displayed in figure 7.

\section{Conclusions}

Single crystals of barium molybdate are grown by isothermal evaporation of lithium chloride flux. Crystal morphology, size and quality are sensitive to the composition of the starting material and soak times. The observed microstructures indicate that the screw dislocation mechanism may not operate in these crystals; the crystals possibly grow by the mechanism of two-dimensional nucleation and propagation 
of growth layers. The crystals are better, both in respect of size and quality, than those obtained by hydrothermal and other flux methods.

\section{Acknowledgement}

One of the authors (GSTR) thanks CSIR, New Delhi for the award of a fellowship.

\section{References}

Authier A 1972 J. Cryst. Grozth 13/14 34

Chase A B $1968 \mathrm{~J}$. Am. Ceram. Soc. 51567

Cho S A, Gomez J A, Camisothi R and Ohep J C 1977 J. Mater. Sci. 12816.

Elwell D and Dawson R $1972 \mathrm{~J}$. Cryst. Growth 13/14 555

Litvin B N, Dem'yanets L N and Garshina L, S 1966 Growth of crystals (eds) A V Shubnikov and N N Sheftal (New York: Consultants Bureau) Vol. 4 p. 134.

Packter A and Roy B N 1971 Kristall. Tech. 639

Packter A and Roy B N 1975 Kristall. Tech. 10383

Powder Data File 1967 American Society for Testing Materials, Philadelphia, Pennsylvania, Card Number $8-455$

Roy R 1966 Mater. Res. Bull. 1299

Tu Chen 1973 J. Cryst. Growth 2029

Webster F W and White E A D $1969 \mathrm{~J}$. Cryst. Growth 5167

Wood J D C and White E A D $1968 \mathrm{~J}$. Cryst. Groteth 3/4 480

Wycoff R W G 1951 Crystal structures (New York: Interscience) 